\title{
Novel Semicarbazone-Based Amidoalkylation Reagents: Preparation and Application to the Stereoselective Synthesis of 14-Membered Hexaaza Macrocycles
}

\author{
Anastasia A. Fesenko, Alexander N. Yankov, Anatoly D. Shutalev* \\ Moscow Technological University, 86 Vernadsky Ave., 119571 Moscow, Russian Federation
}

\begin{abstract}
An efficient general synthesis of hydrazones of 4-(3-oxobutyl)semicarbazones using novel semicarbazone-based amidoalkylation reagents has been developed. The prepared hydrazones were converted under acidic conditions into 14-membered cyclic bis-semicarbazones, 1,2,4,8,9,11hexaazacyclotetradeca-7,14-diene-3,10-diones. Plausible pathway and stereochemistry of the macrocyclization are discussed.
\end{abstract}

\section{Keywords}

Semicarbazones; 4-(Tosylmethyl)semicarbazones; Hydrazones; Azamacrocycles; Amidoalkylation; retro-Claisen reaction; Heterocyclization

\section{Introduction}

Polyaza macrocycles are of considerable importance in various fields of chemistry, biochemistry, medicine, and material science. The unique features of these heterocycles arise from their ability to bind to different inorganic and organic cations, anions, and neutral molecules. ${ }^{1,2}$ Polyaza macrocycles and their metal complexes possess a wide range of biological activities ${ }^{3}$ including anticancer, ${ }^{4}$ anti$\mathrm{HIV}^{5}$ antibacterial and antifungal properties. ${ }^{6}$ The metal complexes also have applications as contrast agents for magnetic resonance imaging, ${ }^{7}$ radiopharmaceuticals, ${ }^{8}$ sensors, ${ }^{9}$ NMR shift reagents, ${ }^{10}$ luminescent materials, ${ }^{9 \mathrm{c}, 10 \mathrm{~b}}$ and catalysis. ${ }^{2 \mathrm{~d}, 11}$

Although a large variety of polyaza macrocycles have been synthesized, the design of new members, particularly tetradentate 14-membered hexaazacycles, is a topic of great interest. Among them, 14-membered 1,2,4,8,9,11-hexaaza macrocycles remain underexploited. ${ }^{12}$ Recently, we reported a general approach to novel 14-membered cyclic bis-semicarbazones $\mathbf{1}$ based on the acid-catalyzed cyclization of 4-(3-oxobutyl)semicarbazide hydrazones 2 (Scheme 1). ${ }^{13}$ 


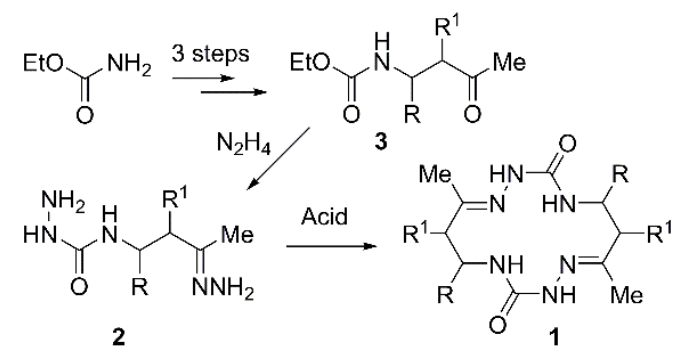

Scheme 1. Synthesis of hexaaza macrocycles $1 .^{13}$

In contrast to 14-membered 1,2,4,8,9,11-hexaaza macrocycles previously described in the literature, ${ }^{12}$ compounds $\mathbf{1}$ are conformationally more flexible because they possess only two double bonds in the heterocyclic ring. Powder X-ray diffraction analysis ${ }^{13 a}$ and DFT calculations showed that the internal cavity of macrocycles $\mathbf{1}$ is able to chelate various metal cations through the N1, N4, N8, and N11 atoms. Indeed, the neutral complex of dianion of $\mathbf{1}\left(\mathrm{R}=\mathrm{Ph}, \mathrm{R}^{1}=\mathrm{H}\right)$ with $\mathrm{Ni}(\mathrm{II})$ was obtained, ${ }^{14}$ demonstrating that hexaaza macrocycles $\mathbf{1}$ can serve as novel tetradentate ligands for metal ions. However, progress in this area was hampered by the low availability of macrocycle precursors 2 which were prepared in four steps from ethyl carbamate involving $\alpha$-amidoalkylation of sodium acetylacetonates with ethyl $N$-(tosylmethyl)carbamates. The Achilles' heel of the synthesis was the low isolated yields (29-42\%) for the substitution of the ethoxy group in $\beta$-carbamato ketones 3 on hydrazino fragment due to the harsh reaction conditions $\left(\mathrm{N}_{2} \mathrm{H}_{4}\right.$, reflux, 20-24 h). ${ }^{13 \mathrm{~b}}$

We hypothesized that hydrazones $\mathbf{2}$ could be readily prepared from N1-protected semicarbazides following the same strategy. Additionally, treatment of 4-(3-oxobutyl)semicarbazides with hydrazine could give access not only to N1-unprotected semicarbazide hydrazones 2, but N1-protected analogues which could also serve as macrocycle precursors.

Herein, we describe a convenient multi-gram synthesis of hydrazones of 4-(3-oxobutyl)-substituted semicarbazides and semicarbazones from 1-arylidenesemicarbazides, and the acid-catalyzed stereoselective cyclization of these hydrazones to give 14-membered cyclic bis-semicarbazones $\mathbf{1}$. The preparation of novel $\alpha$-amidoalkylation reagents, 1-arylidene-4-(tosylmethyl)semicarbazides, is also reported.

\section{Results and discussion}

Based on previous experience, ${ }^{13 b, 15}$ the amidoalkylation reagents $4 \mathbf{a}-\mathbf{d}$ were obtained by the threecomponent condensation of (E)-1-arylidenesemicarbazides 5a-d with the corresponding aromatic aldehydes 6a-d and $p$-toluenesulfinic acid (7) (Scheme 2). Under optimized reaction conditions (EtOH, rt, 3-8 days, 30-50 mol\% excess of 6 and 7), (E)-semicarbazones 4a-d were isolated in 96-99\% yield with $>95 \%$ purity $\left({ }^{1} \mathrm{H}\right.$ NMR) after filtration of the precipitate formed after reaction completion. 


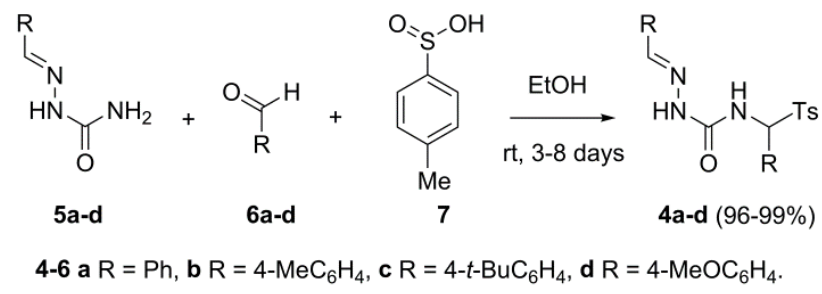

Scheme 2. Synthesis of semicarbazone-based amidoalkylation reagents 4a-d.

It should be noted that the prepared semicarbazones 4a-d represent novel amidoalkylation reagents ${ }^{16}$ and can be widely used in organic synthesis. ${ }^{17}$

Nucleophilic substitution of the tosyl-group in sulfones 4a-d proceeded smoothly under the action of the Na-enolate of acetylacetone in $\mathrm{MeCN}$ to give the corresponding (E)-semicarbazones 8a-d in 9798\% yields (Scheme 3). Treatment of compounds 8a-d with $\mathrm{KOH}$ (5 equiv.) in aqueous $\mathrm{EtOH}$ at room temperature for 3-6 h afforded (E)-4-(3-oxobutyl)semicarbazones 9a-d in 95-97\% yields.

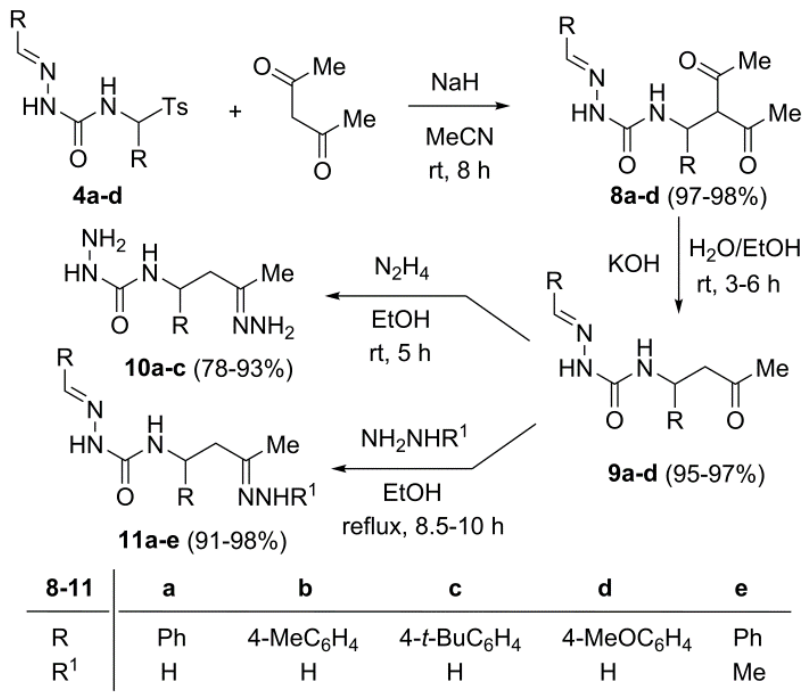

Scheme 3. Synthesis of macrocyclic precursors 10a-c and 11a-e.

Heating compounds 9a-c in EtOH at reflux for 8.5-10 h in the presence of $\mathrm{N}_{2} \mathrm{H}_{4} \cdot \mathrm{H}_{2} \mathrm{O}$ (30 equiv.) afforded hydrazones of semicarbazides 10a-c (78-93\%) as mixtures of $(E)$ - and (Z)-isomers in ratios of 92:8, 94:4, and 95:5, respectively. Under all conditions tested, MeO-derivative 9d failed to give the desired hydrazone with sufficient purity. Thus, compounds 10a-c, the key precursors of 14-membered hexaaza macrocycles, were prepared in four steps from semicarbazones 5a-c in 71-83\% overall yield on a multi-gram scale, while the overall yields of these compounds obtained in four steps from ethyl carbamate (see Scheme 1) were only $22-32 \% .^{13 b}$ 
Treatment of semicarbazones 9a-d with $\mathrm{N}_{2} \mathrm{H}_{4} \cdot \mathrm{H}_{2} \mathrm{O}$ (30 equiv.) in EtOH at room temperature for $5 \mathrm{~h}$ gave mixtures of $(E)$ - and $(Z)$-hydrazones of $(E)$-semicarbazones 11a-d in high yield (94-98\%), with significant predominance of the $(E)$-isomer (91-98\%). Analogously, a 92:8 mixture of $(E)$ - and $(Z)$ methylhydrazones of $(E)$-semicarbazone 11e was obtained in $91 \%$ yield from the reaction of compound 9a with methylhydrazine. The configurations of the major and minor isomers of compounds 11a,c were unambiguously determined using ${ }^{1} \mathrm{H},{ }^{1} \mathrm{H}$ NOESY experiments in DMSO- $d_{6}$. For the major isomer of 11a,c, a diagnostic NOE was observed between the $\mathrm{CH}_{3}$ and $\mathrm{C}=\mathrm{NNH}_{2}$ protons, thus indicating the $(E)$ configuration of the $\mathrm{C}=\mathrm{N}$ double bond in this isomer. Since the ${ }^{1} \mathrm{H}$ and ${ }^{13} \mathrm{C}$ NMR spectra of the major isomers of 11a,c and 11b,d,e were similar, we concluded that the major isomers of $\mathbf{1 1 b}, \mathbf{d}, \mathbf{e}$ also had the (E)-configuration.

Recently, we reported the TsOH-catalyzed transformation of hydrazones 10a-c into hexaaza macrocycles 12a-c (Scheme 4). ${ }^{13}$ The reaction proceeded smoothly in EtOH or MeCN at room temperature or at reflux to give compounds 12a-c in $85-93 \%$ yields as mixtures of trans- and cisisomers whose ratio was dependent on the reaction conditions. Thus, the effective synthesis of the key precursors 10a-c on a multi-gram scale as described herein, provides an improved access to macrocycles 12a-c.

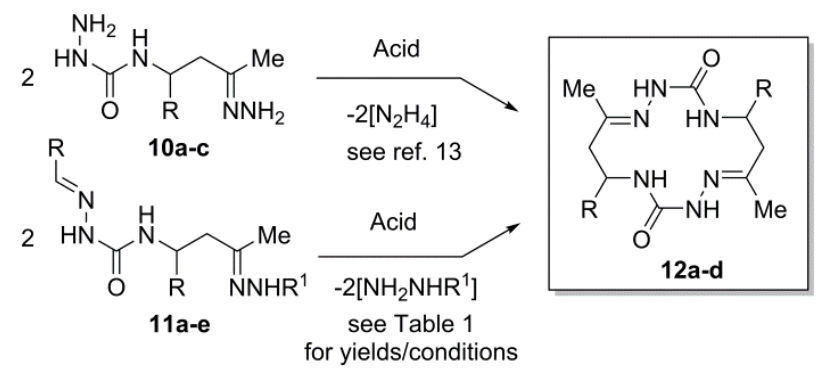

Scheme 4. Syntheses of 14-membered hexaaza macrocycles 12a-d.

Having successfully prepared the hydrazones of semicarbazones 11a-e, we took on the challenge to transform them into the corresponding macrocycles 12a-d. Under optimal conditions for the cyclization of hydrazone 10a (1.07 equiv. of TsOH, EtOH, reflux, 2 h), ${ }^{13 b}$ compound 11a predominantly afforded semicarbazone 5a, and no macrocycle was detected $\left({ }^{1} \mathrm{H}\right.$ NMR). The reaction of 11a with 0.09 equivalents of $\mathrm{TsOH}(\mathrm{EtOH}$, reflux, $2 \mathrm{~h}$ ) resulted in the formation of a complex mixture containing 12a $\left(24 \%{ }^{1} \mathrm{H}\right.$ NMR estimated yield of 12a, trans/cis $\left.=57: 43\right)$.

We found that the macrocyclization of 11 a proceeded well in aprotic solvents (Table 1). In MeCN at reflux, under the action of $\mathrm{TsOH}$ (0.10 equiv.), a 89:11 mixture of trans-and cis-12a was cleanly formed from semicarbazone 11a in $72 \%$ yield (Entry 1). Increasing the concentration of 11a led to an increase in the cyclization stereoselectivity (Entry 2 vs Entry 1). Decreasing the concentration of 11a 
resulted in a higher yield of 12a and lower reaction stereoselectivity (Entry 7 vs Entry 1). Use of an increased amount of TsOH improved both the selectivity and yield of the cyclization (Entry 2 vs Entry 6). When the reaction of $\mathbf{1 1 a}$ with $\mathrm{TsOH}$ was performed in THF, the yield of $\mathbf{1 2 a}$ increased while the stereoselectivity remained unchanged compared with those in MeCN (Entry 2 vs Entry 5).

Table 1. Acid-catalyzed cyclization of semicarbazones 11a-d to give 14-membered hexaaza macrocycles 12a-d. ${ }^{\mathrm{a}}$

\begin{tabular}{|c|c|c|c|c|c|c|c|c|c|}
\hline Entry & $\begin{array}{l}\text { Starting } \\
\text { compound }\end{array}$ & $\mathrm{R}$ & $\begin{array}{l}\text { Conc. } \\
(\mathrm{mol} / \mathrm{L})\end{array}$ & Solvent & Acid (equiv.) & $\begin{array}{l}\text { Time } \\
\text { (h) }\end{array}$ & Product & $\begin{array}{l}\text { trans/cis } \\
\text { ratio }^{\mathrm{b}}\end{array}$ & $\begin{array}{l}\text { Yield }^{\mathrm{c}} \\
(\%)\end{array}$ \\
\hline 1 & $11 a$ & $\mathrm{Ph}$ & 0.123 & $\mathrm{MeCN}$ & $\mathrm{TsOH} \cdot \mathrm{H}_{2} \mathrm{O}(0.10)$ & 2 & $12 \mathbf{a}$ & $89: 11$ & 72 \\
\hline 2 & $11 a$ & $\mathrm{Ph}$ & 0.217 & $\mathrm{MeCN}$ & $\mathrm{TsOH} \cdot \mathrm{H}_{2} \mathrm{O}(0.10)$ & 1 & $12 \mathbf{a}$ & $93: 7$ & 70 \\
\hline 3 & $11 a$ & $\mathrm{Ph}$ & 0.218 & $\mathrm{MeCN}$ & $\mathrm{CF}_{3} \mathrm{COOH}(0.10)$ & 2 & $12 \mathbf{a}$ & $95: 5$ & 77 \\
\hline 4 & $11 a$ & $\mathrm{Ph}$ & 0.157 & $\mathrm{MeCN}$ & $\mathrm{AcOH}(50)$ & 9 & $12 \mathbf{a}$ & $20: 80$ & $14^{\mathrm{d}}$ \\
\hline 5 & $11 a$ & $\mathrm{Ph}$ & 0.195 & $\mathrm{THF}$ & $\mathrm{TsOH} \cdot \mathrm{H}_{2} \mathrm{O}(0.10)$ & 4 & $12 \mathbf{a}$ & $93: 7$ & 78 \\
\hline 6 & $11 a$ & $\mathrm{Ph}$ & 0.243 & $\mathrm{MeCN}$ & $\mathrm{TsOH} \cdot \mathrm{H}_{2} \mathrm{O}(0.20)$ & 2 & $12 \mathbf{a}$ & $97: 3$ & 75 \\
\hline 7 & $11 a$ & $\mathrm{Ph}$ & 0.039 & $\mathrm{MeCN}$ & $\mathrm{TsOH} \cdot \mathrm{H}_{2} \mathrm{O}(0.10)$ & 2 & $12 \mathbf{a}$ & $54: 46$ & 87 \\
\hline 8 & 11b & 4- $\mathrm{MeC}_{6} \mathrm{H}_{4}$ & 0.125 & $\mathrm{MeCN}$ & $\mathrm{TsOH} \cdot \mathrm{H}_{2} \mathrm{O}(0.10)$ & 2 & $12 b$ & $26: 74$ & 68 \\
\hline 9 & $11 b$ & 4- $\mathrm{MeC}_{6} \mathrm{H}_{4}$ & 0.243 & $\mathrm{MeCN}$ & $\mathrm{TsOH} \cdot \mathrm{H}_{2} \mathrm{O}(0.10)$ & 2 & $12 b$ & $64: 36$ & 79 \\
\hline 10 & $11 b$ & 4- $\mathrm{MeC}_{6} \mathrm{H}_{4}$ & 0.243 & $\mathrm{MeCN}$ & $\mathrm{TsOH} \cdot \mathrm{H}_{2} \mathrm{O}(0.10)$ & 1 & $12 b$ & $46: 54$ & 79 \\
\hline 11 & 11b & 4- $\mathrm{MeC}_{6} \mathrm{H}_{4}$ & 0.207 & $\mathrm{MeCN}$ & $\mathrm{CF}_{3} \mathrm{COOH}(0.11)$ & 2 & $12 b$ & $63: 37$ & 80 \\
\hline 12 & $11 b$ & 4- $\mathrm{MeC}_{6} \mathrm{H}_{4}$ & 0.223 & $\mathrm{MeCN}$ & $\mathrm{TsOH} \cdot \mathrm{H}_{2} \mathrm{O}(0.10)$ & 6 & $12 b$ & $96: 4$ & 80 \\
\hline 13 & $11 b$ & $4-\mathrm{MeC}_{6} \mathrm{H}_{4}$ & 0.216 & $\mathrm{MeCN}$ & $\mathrm{TsOH} \cdot \mathrm{H}_{2} \mathrm{O}(0.20)$ & 4 & $12 b$ & $98: 2$ & 78 \\
\hline 14 & 11c & 4- $t-\mathrm{BuC}_{6} \mathrm{H}_{4}$ & 0.119 & $\mathrm{MeCN}$ & $\mathrm{TsOH} \cdot \mathrm{H}_{2} \mathrm{O}(0.09)$ & 1 & $12 \mathrm{c}$ & $49: 51$ & 75 \\
\hline 15 & 11c & 4- $t-\mathrm{BuC}_{6} \mathrm{H}_{4}$ & 0.118 & $\mathrm{MeCN}$ & $\mathrm{TsOH} \cdot \mathrm{H}_{2} \mathrm{O}(0.10)$ & 4 & $12 \mathrm{c}$ & $59: 41$ & 70 \\
\hline 16 & 11c & 4- $t-\mathrm{BuC}_{6} \mathrm{H}_{4}$ & 0.116 & $\mathrm{MeCN}$ & $\mathrm{TsOH} \cdot \mathrm{H}_{2} \mathrm{O}(0.20)$ & 4 & $12 \mathrm{c}$ & $78: 22$ & 68 \\
\hline 17 & 11c & 4- $t-\mathrm{BuC}_{6} \mathrm{H}_{4}$ & 0.119 & $\mathrm{MeCN}$ & $\mathrm{TsOH} \cdot \mathrm{H}_{2} \mathrm{O}(0.20)$ & 8 & $12 \mathrm{c}$ & 100:0 & 92 \\
\hline 18 & 11d & $4-\mathrm{MeOC}_{6} \mathrm{H}_{4}$ & 0.204 & $\mathrm{MeCN}$ & $\mathrm{TsOH} \cdot \mathrm{H}_{2} \mathrm{O}(0.20)$ & 2 & $12 d$ & $97: 3$ & 58 \\
\hline 19 & 11d & $4-\mathrm{MeOC}_{6} \mathrm{H}_{4}$ & 0.210 & $\mathrm{MeCN}$ & $\mathrm{TsOH} \cdot \mathrm{H}_{2} \mathrm{O}(0.10)$ & 4 & 12d & $99: 1$ & 60 \\
\hline
\end{tabular}

${ }^{\text {a }}$ Reaction conditions: MeCN or THF, reflux, 1-9 h.

${ }^{\mathrm{b}}$ According to ${ }^{1} \mathrm{H}$ NMR spectroscopy of the crude product.

${ }^{\mathrm{c}}$ Isolated yield.

${ }^{\mathrm{d}}$ NMR estimated yield.

The stereoselective transformation of 11a into 12a was also promoted by the strong acid TFA (Entry 3). However, only a small amount of 12a (14\% ${ }^{1} \mathrm{H}$ NMR estimated yield, trans/cis = 20:80) along with numerous side-products was obtained in the presence of the relatively weak acetic acid (50 equiv., MeCN, reflux, 9 h) (Entry 4).

Previously, we found that the macrocyclization of semicarbazide 10a in the presence of $\mathrm{TsOH}$ completed in $\mathrm{EtOH}$ at room temperature for $4 \mathrm{~h} .{ }^{13 \mathrm{~b}}$ In contrast, the TsOH-catalyzed conversion of 11a into 12a at room temperature was slow. The crude product obtained after treatment of 11a with TsOH (0.10 equiv.) in MeCN (rt, $24 \mathrm{~h}$ ) contained starting material (3 mol\%), macrocycle 12a (42\% ${ }^{1} \mathrm{H}$ NMR estimated yield, trans/cis $=67: 33$ ) and unidentified compounds.

Thus, under the optimal conditions (Entry 6), macrocycle 12a was obtained in $75 \%$ yield as a $97: 3$ mixture of trans- and cis-isomers. Analogously, reaction conditions were optimized for the transformation of 11b-d into the corresponding macrocycles 12b-d (Table 1). These compounds were prepared in good yields (60-92\%) and with excellent trans-selectivity (up to 100\%). It is noteworthy, that under the optimal conditions, the stereoselectivity for formation of macrocycles $\mathbf{1 2}$ from the hydrazones of semicarbazones $\mathbf{1 1}$ was significantly higher than that from the hydrazones of semicarbazides $\mathbf{1 0}{ }^{13 \mathrm{~b}}$ 
Table 1 shows that the trans-stereoselectivity of the macrocyclization of compounds 11a-d increases with an increase in starting material concentration, reaction time, and catalyst loading. Therefore, we propose that the reaction of 11a-d initially proceeds rapidly with low diastereoselectivity to give mixtures of cis- and trans-12a-d which is then followed by a slow irreversible transformation of the cis-isomers into the trans-isomers via ring opening by a retro-aza-Michael reaction. Calculations performed at the DFT B3LYP/6-311++G(d,p) level of theory using the PCM solvation model showed that trans-12a was less stable than cis-12a in both $\mathrm{MeCN}$ and $\mathrm{EtOH}$ solutions $(\Delta \mathrm{G}=1.67$ and 2.08 $\mathrm{kcal} / \mathrm{mol}$, respectively; $298 \mathrm{~K}$ and $1 \mathrm{~atm})$. The predominant formation of trans-12a-d from 11a-d can be explained by their significantly lower solubility compared with that of cis-isomers; therefore, trans12a-d completely precipitates from the reaction media resulting in a gradual increase in the transselectivity of the process.

Acid-catalyzed macrocyclization of $N$-methylhydrazone 11e could proceed via two possible pathways involving nucleophilic participation of the N1-atom to give macrocycle 12a or the NHMe nitrogen atom to give 2,9-dimethyl derivative of 12a. At reflux for $2.5 \mathrm{~h}$ or at room temperature for 96 $\mathrm{h}$ in $\mathrm{MeCN}$ in the presence of $\mathrm{TsOH}$ (0.10 equiv.), compound 11e afforded macrocycle 12a along with various side and intermediate products $\left({ }^{1} \mathrm{H}\right.$ NMR). Prolonging the reaction time at reflux to $9 \mathrm{~h}$ led to predominant formation of 12a (trans: cis $=58: 42$ ). No ${ }^{1} \mathrm{H}$ NMR signals of the 2,9-dimethyl derivative of 12a were observed.

The presence of the hydrazone fragment in the starting semicarbazones $\mathbf{1 1}$ was proved to be essential for the formation of the macrocycles. Indeed, treatment of 9a with $\mathrm{TsOH}(0.10$ equiv. $)$ in $\mathrm{EtOH}(2 \mathrm{~h})$ or $\mathrm{MeCN}(4 \mathrm{~h})$ at reflux resulted in partial decomposition of the starting material to give semicarbazone 5a, benzylideneacetone, and unidentified products without any formation of macrocycle 12a $\left({ }^{1} \mathrm{H}\right.$ NMR). The starting material was completely recovered after reflux of $9 \mathbf{a}$ in EtOH for $3 \mathrm{~h}$ in the presence of $\mathrm{AcOH}$ (4.06 equiv.).

Thus, the experimental data show that the macrocyclization of 11a-e proceeds via nucleophilic attack of the N1 nitrogen atom of one molecule on the electrophilic carbon of the hydrazone moiety of the second molecule after its activation by the catalyst. However, the nucleophilicity of the N1 atom with $\mathrm{sp}^{2}$-hybridization is not sufficient for the cyclization. We propose that under the examined reaction conditions, a more nucleophilic $\mathrm{sp}^{3}$-hybridized nitrogen is generated by the addition of a nucleophile to the $\mathrm{C}=\mathrm{N}$ double bond, for example, the water from $\mathrm{TsOH} \cdot \mathrm{H}_{2} \mathrm{O}$. A plausible pathway for the $\mathrm{TsOH} \cdot \mathrm{H}_{2} \mathrm{O}$-catalyzed macrocyclization of hydrazones 11a-e is shown in Scheme 5. 


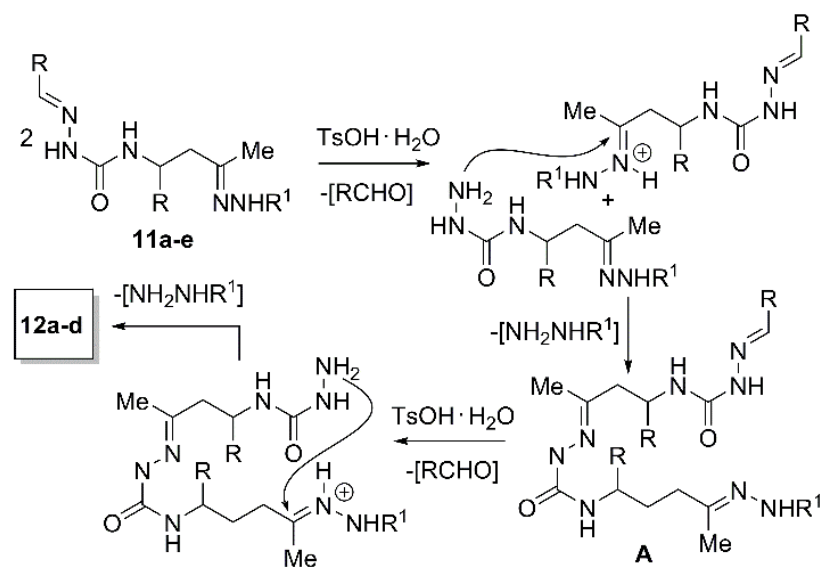

Scheme 5. Plausible pathway for the macrocyclization of semicarbazones 11a-e.

This pathway involves hydrolytic cleavage of the semicarbazone moiety followed by reaction of the free $\mathrm{NH}_{2}$-group of the obtained semicarbazide with the protonated hydrazone fragment of second molecule to give acyclic intermediate $\mathbf{A}$ which cyclizes into the product $\mathbf{1 2}$ following the same steps.

\section{Conclusion}

In conclusion, a stereoselective five-step synthesis of novel 14-membered bis-semicarbazones based on the acid-catalyzed cyclization of hydrazones of 4-(3-oxobutyl)semicarbazides or 4-(3oxobutyl)semicarbazones has been developed. Hydrazones were obtained by an efficient multi-gram protocol from novel amidoalkylation reagents, 1-arylidene-4-(tosylmethyl)semicarbazides, whose simple preparation was also described.

\section{Acknowledgments}

This research was financially supported by the Russian Foundation for Basic Research (Grant No. 1503-07564) and the Ministry of Education and Science of the Russian Federation (basic part of government order, 4.9671.2017).

\section{References and Notes}

1. For selected books on polyaza macrocycles, see: (a) Macrocyclic Chemistry: New Research Developments; Fitzpatrick, D. W., Ulrich, H. J., Eds.; Nova Science Publishers, Inc.: New York, 2010. (b) Hermann, P.; Kotek, J. Ten-membered Rings or Larger with One or More Nitrogen Atoms, in Comprehensive Heterocyclic Chemistry III; Elsevier: Amsterdam, 2008; Vol. 14, pp 613-665. (c) Macrocyclic Chemistry: Current Trends and Future Perspectives; Gloe, K., Ed.; Springer: New York, 2005. (d) Lindoy, L. F. The Chemistry of Macrocyclic Ligand Complexes; 
Cambridge University Press: Cambridge, 1989. (e) Coordination Chemistry of Macrocyclic Compounds; Melson, G., Ed.; Plenum Press: New York, 1979.

2. For some reviews on binding properties of polyaza macrocycles, see: (a) Gavey, E. L.; Pilkington, M. Coord. Chem. Rev. 2015, 296, 125-152; (b) Geduhn, J.; Walenzyk, T.; König, B. Curr. Org. Synth. 2007, 4, 390-412; (c) Radecka-Paryzek, W.; Patroniak, V.; Lisowski, J. Coord. Chem. Rev. 2005, 249, 2156-2175; (d) Reichenbach-Klinke, R.; König, B. J. Chem. Soc., Dalton Trans. 2002, 121-130; (e) Aoki, S.; Kimura, E. Rev. Mol. Biotechnol. 2002, 90, 129-155; (f) McAuley, A.; Subramanian, S. Coord. Chem. Rev. 2000, 200-202, 75-103; (g) Mitewa, M.; Bontchev, P. R. Coord. Chem. Rev. 1994, 135-136, 129-163.

3. For reviews on biological activities of polyaza macrocycles, see (a) Liang, X.; Sadler, P. J. Chem. Soc. Rev. 2004, 33, 246-266; (b) Liang, F.; Wan, S.; Li, Z.; Xiong, X.; Yang, L.; Zhou, X.; Wu, C. Curr. Med. Chem. 2006, 13, 711-727.

4. (a) Cruz, C.; Cairrão, E.; Lourenço, O.; Almeida, P.; Verde, I.; Queiroz, J. A. Chem. Biol. Drug Des. 2013, 81, 517-526; (b) Sibert, J. W.; Cory, A. H.; Cory, J. G. Chem. Commun. 2002, 154-155.

5. De Clercq, E. Nat. Rev. Drug Discovery 2003, 2, 581-587.

6. Sakhare, M. A.; Khillare, S. L.; Lande, M. K.; Arbad, B. R. Adv. Appl. Sci. Res. 2013, 4, 94-100.

7. (a) Aime, S.; Crich, S. G.; Gianolio, E.; Giovenzana, G. B.; Tei, L.; Terreno, E. Coord. Chem. Rev. 2006, 250, 1562-1579; (b) De León-Rodríguez, L. M.; Ortiz, A.; Weiner, A. L.; Zhang, S.; Kovacs, Z.; Kodadek, T.; Sherry, A. D. J. Am. Chem. Soc. 2002, 124, 3514-3515.

8. (a) Smith, C. J.; Volkert, W. A.; Hoffman, T. J. Nucl. Med. Biol. 2005, 32, 733-740; (b) Heppeler, A.; Froidevaux, S.; Eberle, A. N.; Maecke, H. R. Curr. Med. Chem. 2000, 7, 971-994.

9. (a) Roger, M.; Regueiro-Figueroa, M.; Azzeddine, C. B.; Patinec, V.; Bonnet, C. S.; Platas-Iglesias, C.; Tripier, R. Eur. J. Inorg. Chem. 2014, 1072-1081; (b) El Majzoub, A.; Cadiou, C.; DéchampsOlivier, I.; Chuburu, F.; Aplincourt, M. Eur. J. Inorg. Chem. 2007, 5087-5097; (c) Bünzli, J.-C. G.; Piguet, C. Chem. Soc. Rev. 2005, 34, 1048-1077.

10. (a) Peters, J. A.; Huskens, J.; Raber, D. J. Prog. Nucl. Magn. Reson. Spectrosc. 1996, 28, 283-350;

(b) Parker, D.; Dickins, R. S.; Puschmann, H.; Crossland, C.; Howard, J. A. K. Chem. Rev. 2002, 102, 1977-2010.

11. (a) Salavati-Niasari, M.; Najafian, H. J. Chem. Res. (S) 2003, 538-539; (b) Canales, J.; Ramirez, J.; Estiu, G.; Costamagna, J. Polyhedron 2000, 19, 2373-2381; (c) Costamagna, J.; Ferraudi, G.; Canales, J.; Vargas, J. Coord. Chem. Rev. 1996, 148, 221-248.

12. (a) Arion, V. B.; Gerbeleu, N. V.; Levitsky, V. G.; Simonov, Yu. A.; Dvorkin, A. A.; Bourosh, P. N. J. Chem. Soc., Dalton Trans. 1994, 1913-1916; (b) Vlasiuk, S. V.; Pavlovsky, V. I.; Andronatti, S. A.; Gdaniec, M.; Simonov, Y. A. Chem. Heterocycl. Compd. 2000, 36, 1077-1085; (c) Gradinaru, J. I.; Simonov, Yu. A.; Arion, V. B.; Bourosh, P. N.; Popovici, M. A.; Bel'skii, V. K.; Gerbeleu, N. V. Inorg. Chimica Acta 2001, 313, 30-36; (d) Chaudhary, A.; Joshi, S. C.; Singh, R. V. Main Group 
Met. Chem. 2004, 27, 59-70; (e) Chandra, S.; Gupta, L. K.; Agrawal, S. Transition Met. Chem. 2007, 32, 240-245; (f) Chandra, S.; Gautam, A. J. Serb. Chem. Soc. 2009, 74, 1413-1422; (g) Dolzhenko, A. V.; Pastorin, G.; Dolzhenko, A. V.; Chui, W. K. Tetrahedron Lett. 2009, 50, 56175621.

13. (a) Shutalev, A. D.; Fesenko, A. A.; Kuzmina, O. M.; Volov, A. N.; Albov, D. V.; Chernyshev, V. V.; Zamilatskov, I. A. Tetrahedron Lett. 2014, 55, 5481-5485; (b) Fesenko, A. A.; Shutalev, A. D. Tetrahedron, 2015, 71, 9528-9543.

14. Volov, A. N.; Zamilatskov, I. A.; Chernyshev, V. V.; Savinkina, E. V.; Chuvaev, V. F.; Kurochkina, N. M.; Tsivadze, A. Yu. J. Coord. Chem. 2014, 67, 3121-3134.

15. (a) Shutalev, A. D.; Kishko, E. A.; Sivova, N. V.; Kuznetsov, A. Yu. Molecules 1998, 3, 100-106; (b) Shutalev, A. D.; Kurochkin, N. N. Mendeleev Commun. 2005, 15, 70-72; (c) Fesenko, A. A.; Tullberg, M. L.; Shutalev, A. D. Tetrahedron 2009, 65, 2344-2350; (d) Kurochkin, N. N.; Fesenko, A. A.; Cheshkov, D. A.; Davudi, M. M.; Shutalev, A. D. Tetrahedron Lett. 2011, 52, 88-91; (e) Fesenko, A. A.; Trafimova, L. A.; Shutalev, A. D. Org. Biomol. Chem. 2012, 10, 447-462; (f) Fesenko, A. A.; Shutalev, A. D. J. Org. Chem. 2013, 78, 1190-1207; (g) Fesenko, A. A.; Shutalev, A. D. Tetrahedron 2014, 70, 5398-5414.

16. Generally, amidoalkylation reagents are constructed by using various amides, ureas, thioureas, carbamates, and thiocarbamates as an amide backbone. ${ }^{18}$

17. A large variety of 4-(tosylmethyl)semicarbazones could be prepared by the reaction of $p$ toluenesulfinic acid with aliphatic and aromatic aldehydes and semicarbazones of the same or other aldehydes. The use of these reagents in organic synthesis will be the subject of forthcoming publications.

18. For selected reviews on $\alpha$-amidoalkylation, see: (a) Zaugg, H. E.; Martin, W. B. Org. Reactions 1965, 14, 52-269; (b) Zaugg, H. E. Synthesis 1970, 49-73; (c) Zaugg, H. E. Synthesis 1984, 85110; (d) Zaugg, H. E. Synthesis 1984, 181-212; (e) Speckamp, W. N.; Moolenaar, M. J. Tetrahedron 2000, 56, 3817-3856; (f) Maryanoff, B. E.; Zhang, H.-C.; Cohen, J. H.; Turchi, I. J.; Maryanoff, C. A. Chem. Rev. 2004, 104, 1431-1628; (g) Mazurkiewicz, R.; Październiok-Holewa, A.; Adamek, J.; Zielińska, K. Adv. Heterocycl. Chem. 2014, 111, 43-94. 